\title{
The spectrum of Familial Mediterranean Fever (FMF) mutations
}

\author{
Isabelle Touitou*,1 \\ ${ }^{1}$ Hopital A de Villeneuve, Montpellier, France
}

Familial Mediterranean Fever (FMF) is the prototype of a group of inherited inflammatory disorders. The gene (MEFV) responsible for this disease, comprises 10 exons and 781 codons. Twenty-nine mutations, most located in the last exon, have been identified so far. It is unclear whether all are true disease-causing mutations. Five founder mutations, V726A, M694V, M694I, M680I and E148Q account for 74\% of FMF chromosomes from typical cases (Armenians, Arabs, Jews, and Turks). Rare mutations are preferentially found in populations not usually affected by FMF (eg Europeans not from the above ancestries). The various combinations of MEFV mutations define severe to mild genotypes. The trend is that genotypes including two mutations located within mutational 'hot-spots' (codons 680 or 694) of the gene are associated with severe phenotypes, whereas mild phenotypes are associated with some other mutations, E148Q being the mildest and least penetrant. Understanding the correlation between the FMF phenotype and genotype is further obscured by the existence of complex alleles, modifier loci, genetic heterogeneity and possible epigenetic factors. Additionally, mutations in the MEFV gene are thought to be involved in non FMF disorders. Carrier rates for FMF mutations may be as high as 1:3 in some populations, suggesting that the disease is underdiagnosed. This review update emphasises that both clinical and genetic features are to be taken into account for patient diagnosis, colchicine treatment and prognosis. European Journal of Human Genetics (2001) 9, $473-483$.

Keywords: FMF; mutations; review

\section{Introduction}

The name of Familial Mediterranean Fever (FMF) has been given to this disease because it is a hereditary inflammatory disorder particularly common in populations from Mediterranean ancestry: Armenians, Arabs, Jews, and Turks. ${ }^{1}$ Short self resolving attacks of fever and serositis are the key elements of clinical diagnosis. FMF is classically transmitted as an autosomal recessive trait but rare cases of dominant transmission have been described. The molecular basis of dominant transmission (that was actually most often a

${ }^{*}$ Correspondence: Dr Isabelle Touitou, MD, PhD, Laboratoire de génétique moléculaire et chromosomique, Hôpital A de Villeneuve, 371, Av du doyen Giraud, 34295 Montpellier Cedex 5, France.

Tel: +33467335859; Fax: +33467335862;

E-mail: isabelle.touitou@igh.cnrs.fr

Received 22 November 2000; revised 5 March 2001; accepted 19 March 2001 pseudodominant transmission) was accounted for by (i) a high rate of consanguinity in populations with endogamy habits such as those commonly affected by FMF, (ii) a high carrier rate in those populations, enhancing the risk that the spouse of a FMF patient is a carrier, ${ }^{2,3}$ and (iii) the particular severity of some mutations. ${ }^{4}$

The FMF gene, MEFV, is located on chromosome 16p13.3. It has been identified by positional cloning in the summer of $1997^{5,6}$ and comprises 10 exons. The tenth exon contains the first four mutations reported in FMF. Only 25 novel MEFV mutations have been identified during the last 3 years since the cloning of the gene..$^{2,3,7-15}$ Many explanations may be proposed. Firstly, until now, FMF was only clinically recognised in classically affected populations, in which the disease is due to a limited number of mutations which then expanded through a founder effect. Second, none of the $12-$ 15 laboratories providing FMF genetic testing throughout the world, screens the entire sequence of the gene routinely. 
Finally, genes other than MEFV may be responsible for clinical pictures resembling FMF (FMF-like diseases). Of the 29 known MEFV mutations, 26 are missense mutations, one is a recently found nonsense mutation (Y688X), ${ }^{12}$ and two are small deletions (I692del, M694del). ${ }^{7,11}$ No gross rearrangements have been found so far, presumably because they are lethal or correspond to another phenotype.

The protein encoded by MEFV was called Marenostrin by the French group in reference to the Latin name of the Mediterranean sea, and Pyrin by the International consortium in reference to the Greek name of fever. Marenostrin/ Pyrin is a 781 amino acid protein of a predicted $86 \mathrm{kd}$ molecular weight. It has been thought for a while that Marenostrin/Pyrin was a transcription factor, because of the presence of two nuclear localisation sites in the gene sequence, and because of a strong homology of the predicted protein sequence with a group of zinc-finger DNA binding proteins. ${ }^{5,6}$ However, immunofluorescent staining studies showed that, unexpectedly, the protein was cytoplasmic and colocalised with microtubules. ${ }^{16}$ These data have been challenged recently by the finding of a deleted isoform that specifically binds to the nucleus. ${ }^{17}$ Understanding of the pathophysiology of the disease has also been sought through the study of other species. The predicted rodent proteins have considerable homology with humans, ${ }^{18}$ but do not have an intact $C$ terminal domain, in which most FMFassociated mutations have been found in humans! Identification of the protein function thus remains a difficult task.

The aim of this review is to provide an update of the spectrum of FMF mutations, of the relationship between phenotype and genotype that are beginning to be understood, and of the implications for genetic testing. Since the series dealing with FMF mutations reported in the literature are not perfectly comparable in terms of criteria for patient inclusion ${ }^{19}$ and in terms of mutation screening strategies, a true meta-analysis is not feasible from existing publications. Calculations were thus performed from the data available to date, and include the largest and/or most detailed series published per each investigation centre. Although the mean percentages given here are to be interpreted as rough estimates, they give a comprehensive overview of the situation 3 years after the cloning of the gene.

\section{The spectrum of FMF mutations}

\section{Location of MEFV mutations}

Mutations have been found in exons 1, 2, 3, 5, 9 and 10 of the MEFV gene (Figure 1). There are two apparent mutational 'hot spots': one in exon 2 and one in exon 10. Remarkably, two hot spots are also contained within exon 10, one at codon $680^{13}$ and one at codon $694,^{7}$ without any explanation proposed yet. Three mutations have been identified at each of these two codons, and interestingly $\mathrm{Y} 688 \mathrm{X},{ }^{12}$ the sole premature stop codon found to date in a FMF patient, is located between these two codons. This observation supports the view that this small region is critical for the function of MEFV. In exon 2, two mutations have been found at codon $148 .^{7,8}$

\section{Five frequent mutations}

Haplotype analysis has demonstrated that many modern-day FMF chromosomes are descended from common ancestors, probably dating to pre-biblical times. This founder effect likely accounts for the high prevalence of five rather conservative FMF mutations (Figure 1). The other 24 known mutations are found in no more than $1 \%$ of FMF chromosomes. About a quarter of all FMF alleles are yet to be identified! It is quite likely that a broad number of cases are not MEFV linked and suffer from 'FMF-like' symptoms.

\section{Four classically affected ethnic groups}

The first studies on MEFV mutations had focused on commonly affected populations, namely: Arabs (North Africans ie Maghrebins, and Orientals), Armenians, NonAshkenazi Jews (NAJ ie Sefardim and Orientals) and Turks. The disease is possibly more recognised in these four ethnic groups not only because the prevalence of MEFV mutations is high, but also because their clinical picture is usually complete. M694V is the most frequent mutation in all four populations, ranging from 20 to $65 \%$ (Figure 2).

Comparative studies are now available which further address the spectrum of mutations according to the geographic origin of these patients. In North African Jews (Figure 3), M694V is over represented (71\%), while in East European Jews (Ashkenazim), a milder mutation V726A (see below), is the most frequent (38\%). Interestingly, the prevalence of these two mutations in Oriental Jews is in between that of North African Jews and Ashkenazim, suggesting that M694V and V726A likely spread from the middle East. Arabs have a very diverse mutational pattern depending on their origin. Oriental Arabs have more V726A than Arabs from North Africa, while M694I seems to be relatively specific to Maghrebins (Figure 4). Only $16 \%$ of Armenian patients have unidentified MEFV mutations (Figure 2). No differences in the distribution of MEFV mutations has been detected between Armenian patients from Yerevan and those living in California ${ }^{20}$ or France. $^{21}$

\section{Other ethnic groups}

More recent studies extended MEFV mutation screening to patients from other origins (Figure 5), mostly Europeans not from the ancestries quoted above. Italians, especially those from the South of Italy and Sicily, should no longer be considered as rarely affected populations. A broad range of mutations is found in Italians, the most frequent being E148Q (18\%). In Spanish patients, M694V and E148Q are the first $(32 \%)$ and second (14\%) most frequent mutations respectively, as in NAJ. This is not surprising since most of the NAJ are descendants of Sefardi Jews who were forced to 


\section{The spectrum of MEFV mutations}

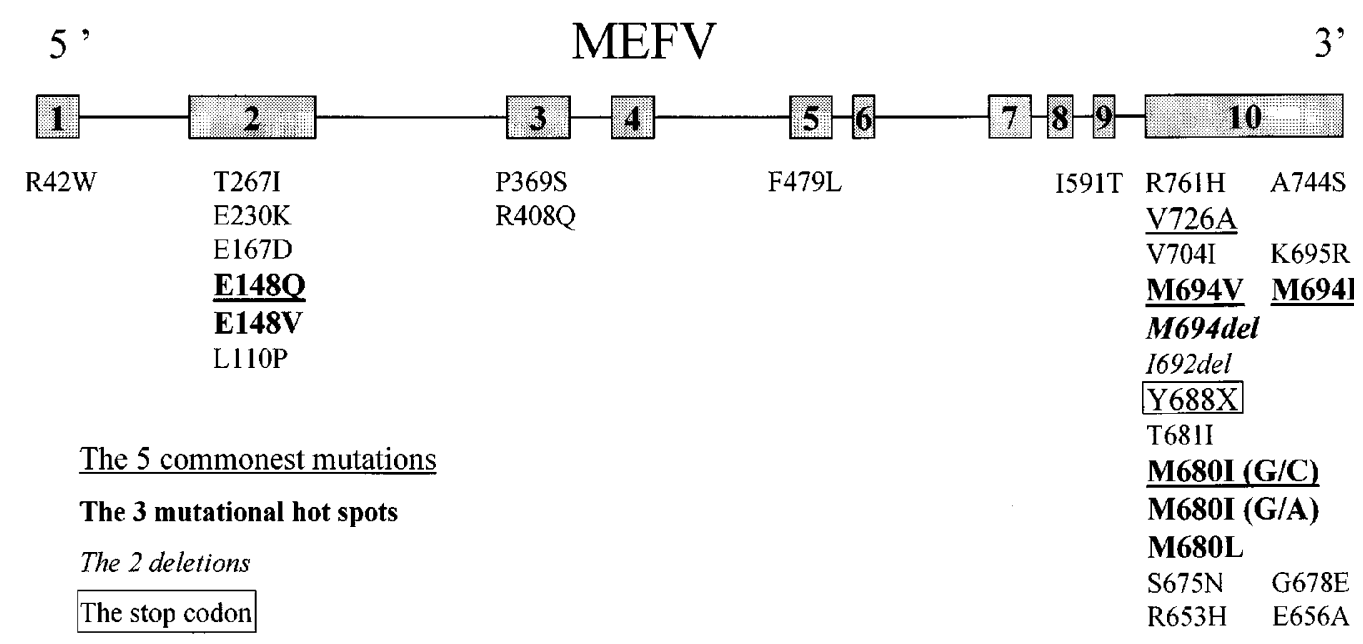

Figure 1 The spectrum of MEFV mutations. The MEFV gene is composed of 10 exons. Twenty-nine disease-associated mutations have been recorded so far. The five most frequent mutations are underlined. Mutations in hot spots are in bold letters. Deletions are with italics letters. The sole nonsense mutation is boxed.

flee Spain in the 15th century (Sefardi means Spain in Hebrew). A number of Portuguese patients have been referred for genetic testing, but V726A was the only mutation found in $17 \%$ of them (data not shown). The distribution of MEFV mutations in Greeks resembles that of Arabs and Italians. Three British FMF families have been described with probably true dominant FMF. ${ }^{4}$ Patients of Indian, Chinese, Afghan and Hungarian origin have also been described, ${ }^{7,11}$ (and I Touitou, personal unpublished data).

Rare mutations and complex alleles

Mutations other than the five described above are each found in $\leqslant 1 \%$ FMF chromosomes, some of them being private (discovered in only one patient). Some rare MEFV mutations tend to be over represented in peculiar populations, but have been occasionally detected in other countries (Table 1). $\mathrm{R} 761 \mathrm{H}$ is rather prevalent in Armenians and Turks, K695R in Jews (NAJ and Ashkenazim), A744S in Arabs and F479L in Armenians. The rare form of M680I (M680IG/A) seems to be quite frequent in Oriental Arabs and Italians. Private mutations are preferentially found in patients not from classic ancestries. In some cases, more than one mutation has been found in a single copy of the MEFV gene. To date, nine complex alleles have been detected, seven including E148Q (Table 1).

\section{Phenotype-genotype correlation}

Clinical heterogeneity is frequent in FMF and relies at least partly on genetic heterogeneity. The clinical panel that has been associated with MEFV mutations ranges from total absence of symptoms (incomplete penetrance), through variable expressivity to severe complications such as amyloidosis.

\section{Allelic heterogeneity}

Severe mutations Currently, the most numerous phenotype-genotype data available relate to M694V (Figure 6). The penetrance of M694V homozygosity is very high (99\%). This genotype has been demonstrated to be correlated with a severe disease course in NAJ, Arabs and Armenians. ${ }^{2,8,22-30}$ Some clinical features are reproducibly more frequent in M694V homozygous patients (amyloidosis, early disease onset, arthritis), whereas others (frequency of attacks, thoracic pain, erysipelas) depend on the series. High fever, splenomegaly, and protracted myalgy were also more frequent in those patients. ${ }^{31,32}$ Unexpectedly though, the presence of M694V was not found to be associated with a severe form of the disease or the development of amyloidosis in an independent series from Ankara. ${ }^{33,34}$ This group recently reported that patients with the G138 polymorphism in exon 2 were more prone to amyloidosis. ${ }^{35}$

Other mutations at codon 694 and mutation M680I are also possibly severe ones. Patients homozygous for M694I, M680I or carrying a combination of mutations at codons 694 and 680 have a disease course as severe as those homozygous for $\mathrm{M} 694 \mathrm{~V} .{ }^{36-38}$ In three British families, deletion of this codon gave rise to a true dominant transmission. ${ }^{4}$

Mild mutations $\mathrm{E} 148 \mathrm{Q}$, one of the five most frequent MEFV mutations, is the least penetrant FMF mutation and is recognised to have a mild effect on FMF patients in all 
Arabs: $\mathrm{N}=706$

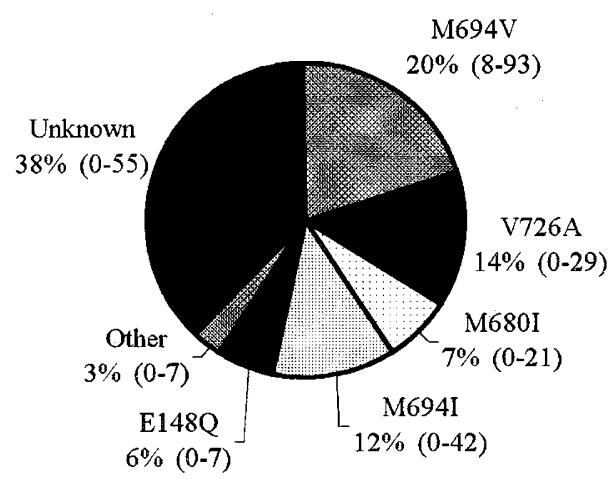

Jews: $\mathrm{N}=1301$

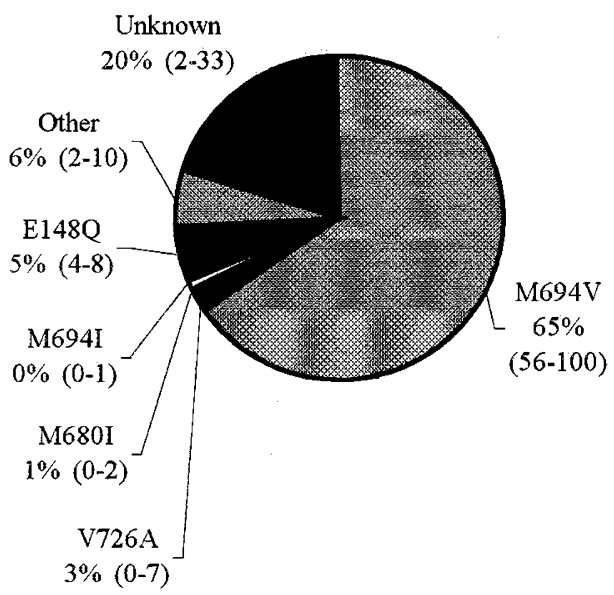

Armenians: $\mathrm{N}=\mathbf{3 7 8}$
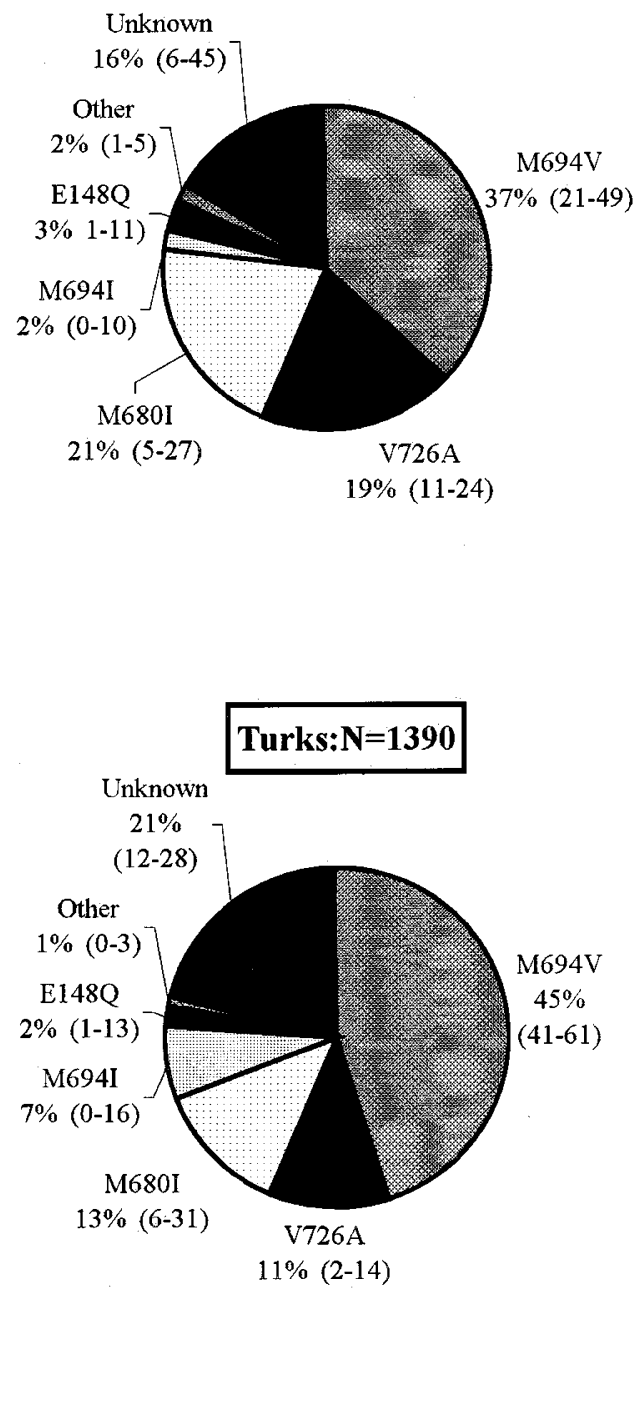

Figure 2 Repartition of MEFV mutations in populations commonly affected by FMF. Data are compiled from personal unpublished sources and references for: (Arabs), ${ }^{3,4,9,11,24,36,38,42,69,70,71}$ (Armenians), ${ }^{2,3,9,11,25,29}$ (Jews), ${ }^{3,9,24,58,67}$ and (Turks). ${ }^{3,4,8,9,11,25,29,30,33,68}$ $\mathrm{N}=$ number of FMF chromosomes scored. Ranges are represented in parenthesis. Zeros refer to either absent or not studied mutations.

reports. $3,7,39-41$ Especially when it is in a homozygous state, individuals are asymptomatic in $55 \%$ of the cases, and amyloidosis has never developed in those patients (Figure 6). However, when E148Q is part of a complex allele, it has been suggested to have an aggravating effect: dominant transmission when allelic to M694I with a second wild type allele, ${ }^{4}$ amyloidosis when allelic to V726A with a second mutated allele. ${ }^{23}$ V726A prevalence is generally higher in populations with mild disease, ${ }^{3,40,42}$ but genotypes including this mutation may be found in patients with amyloidosis. ${ }^{33,34}$ In one Jordanian series however, genotypes including V726A were associated with a more severe disease than those with M680I. ${ }^{43}$ Mild phenotype or incomplete penetrance have also been described in patients with K695R or P369S. ${ }^{3,7}$

Results of MEFV screening studies in the general population are compiled in Table 2. Mutations in exon 10 are far more prevalent in FMF patients than in non FMF individuals. Mutation E148Q in contrast, is slightly more frequent in the general population than in FMF patients, and unexpectedly, 


\section{North-Africans: $\mathbf{N}=\mathbf{1 0 4 9}$}

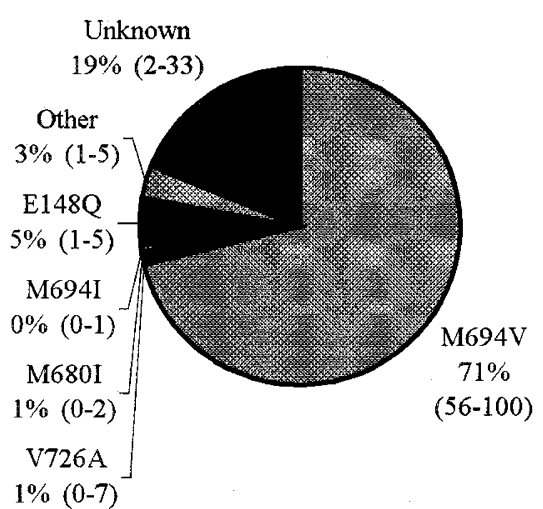

\section{Ashkenazim: $\mathbf{N}=\mathbf{8 7}$}

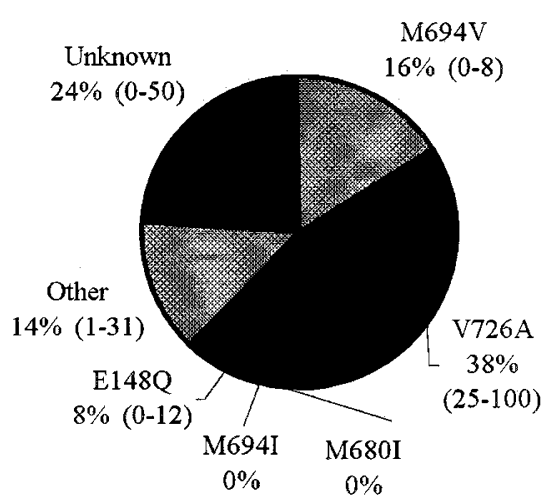

Others: $\mathrm{N}=109$

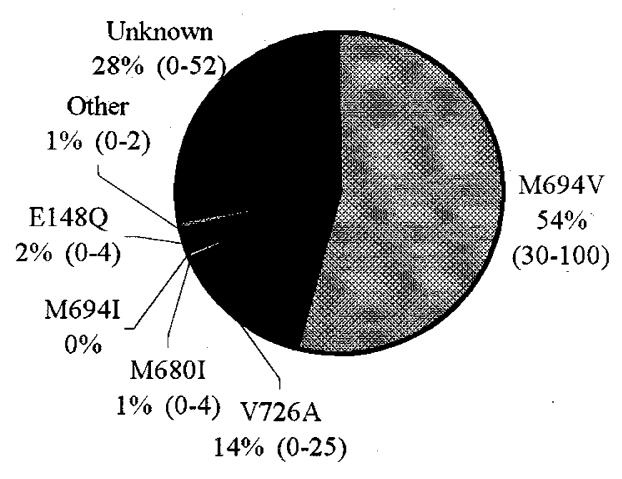

Figure 3 Repartition of MEFV mutations in Jewish FMF patients. Data are compiled from personal unpublished sources and references for: (North-Africans), ${ }^{24,39,58,67}$ (Ashkenazim), ${ }^{3,9,11,58,67}$ (Iraqi), ${ }^{24,42,58}$ and (Others). ${ }^{24,58,67}$ Others include Lybian, Egyptian, Syrian, Turkish, and Greek Jews. $\mathrm{N}$ = number of FMF chromosomes scored. Ranges are represented in parenthesis. Zeros refer to either absent or not studied mutations.

is present in $21 \%$ and $15 \%$ of MEFV genes from Punjabi Indian and Chinese controls respectively, two populations not classically affected by FMF. ${ }^{44}$ It has been proposed that the E148Q mutation is a sequence variant rather than a disease-causing mutation. ${ }^{39}$ Since it may affect the patient phenotype under some still undefined genetic and epigenetic circumstances, we propose to designate it as a 'functional polymorphism'.

\section{Modifiers}

Modifiers are genetic factors that have a mild effect and are not mandatory for the outbreak of the disease. In complex alleles, one mutation may have a modifying effect on the other one. Two MEFV-independent modifying loci have been identified recently. MICA, the Major Histocompatibility Complex class I chain-related gene A, is one of them. ${ }^{45}$ The impact of M694V homozygosity on the age at onset was aggravated if patients also inherited MICA A9, whereas MICA A4 was found to be associated with a milder form of the disease. Another French team demonstrated that susceptibility to renal amyloidosis was enhanced in patients with the SAA-1 alpha/alpha genotype and in males, each factor acting independently. ${ }^{46}$ 


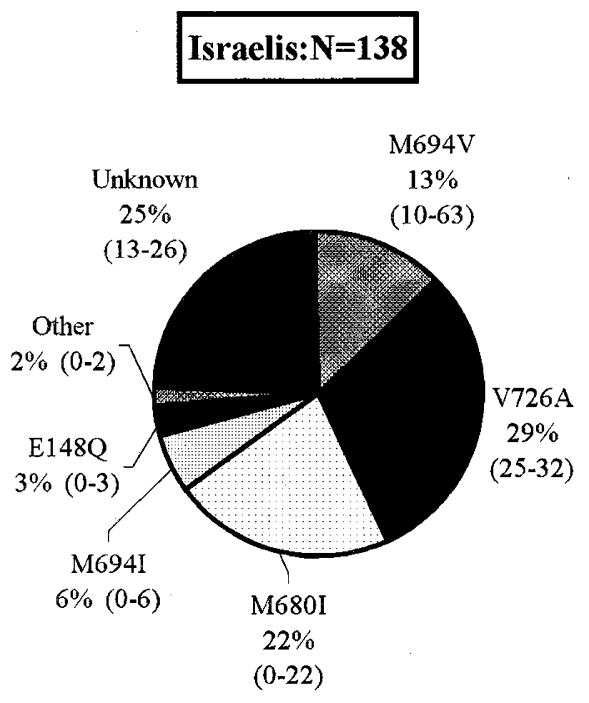

Maghrebins: $\mathrm{N}=198$

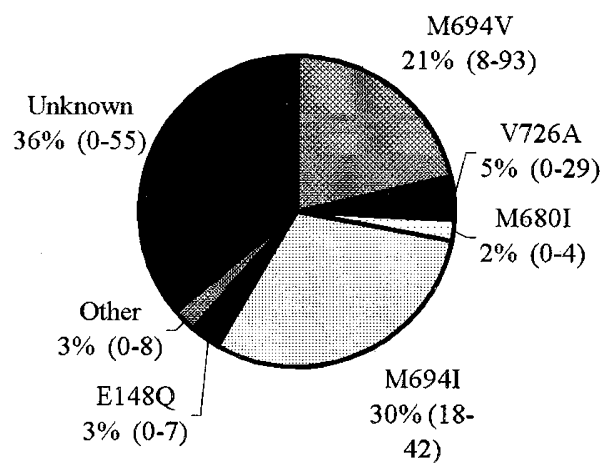

Lebaneses: $N=163$

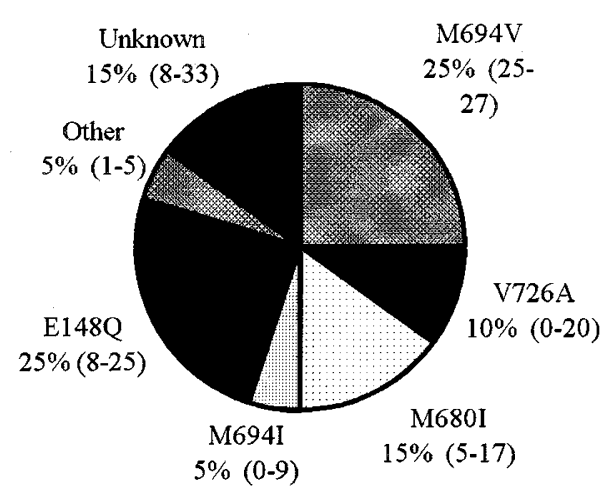

Others: $N=207$

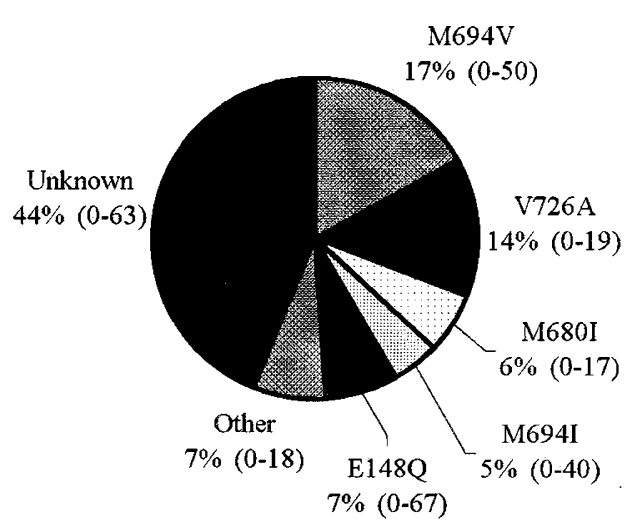

Figure 4 Repartition of MEFV mutations in Arab FMF patients. Data are compiled from personal unpublished sources and references for: (Maghrebins), ${ }^{9}$ (Lebaneses), ${ }^{9,36}$ (Israeli), ${ }^{24,38}$ and (Others). $3,4,11,38,42,60-62,67$ Others include Jordanians, Lybian, Egyptian, Syrian, Iranian, Iraqi Arabs, Druzes and Bedoins. $\mathrm{N}=$ number of FMF chromosomes scored. Ranges are represented in parenthesis. Zeros refer to either absent or not studied mutations.

\section{Locus heterogeneity}

In addition, it has been proposed that another gene may be responsible for some cases of $\mathrm{FMF}^{47}$ since some clinically diagnosed families were not linked to the chromosomal region containing MEFV.

\section{MEFV mutations and other inflammatory diseases}

A growing set of data led to the hypothesis that the MEFV gene may be involved in non FMF conditions. A high prevalence of MEFV mutations has been demonstrated in patients suffering from Behcet disease, ${ }^{48,49}$ non-FMF secondary amyloidosis (eg Rheumatoid Arthritis), ${ }^{50}$ recurrent abdominal pain. ${ }^{51}$ More- over, some polyfactorial inflammatory diseases are more frequent in FMF patients than in the ethnically matched general population: Inflammatory bowel disease, ${ }^{52,53}$ Behcet disease. ${ }^{54}$ It has been suggested that some MEFV mutations may non-specifically upregulate the inflammatory response. ${ }^{44}$ This hypothesis is further supported by the fact that acute phase reactants are enhanced in asymptomatic individuals with one ${ }^{55}$ or two ${ }^{56}$ MEFV mutations.

\section{Conclusion}

A number of observations, if confirmed, will have direct implication for FMF diagnosis, treatment and prognosis. The 


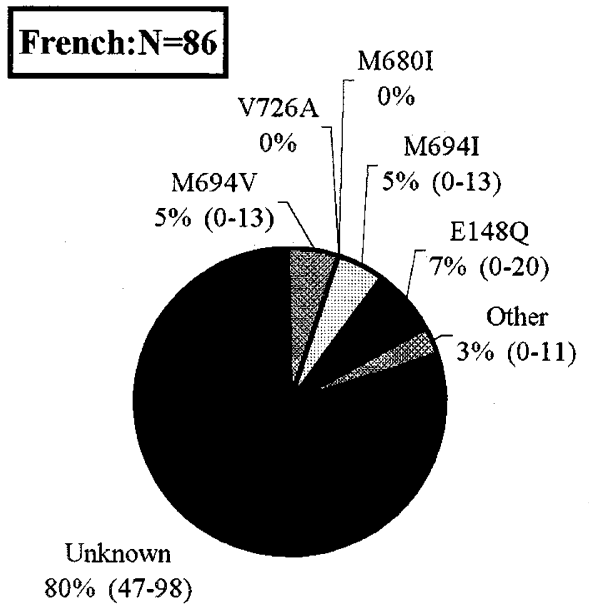

\section{Spaniards: $\mathbf{N}=\mathbf{4 2}$}

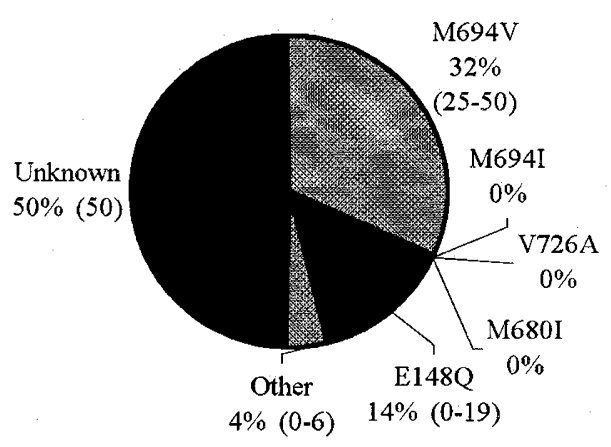

\section{Italians: $\mathbf{N}=\mathbf{6 2}$}

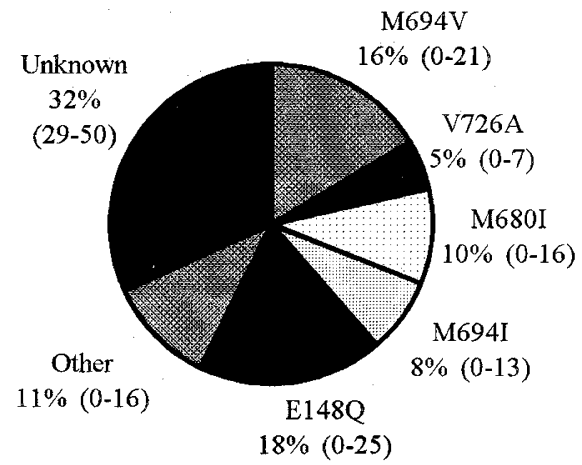

Greeks:N=16

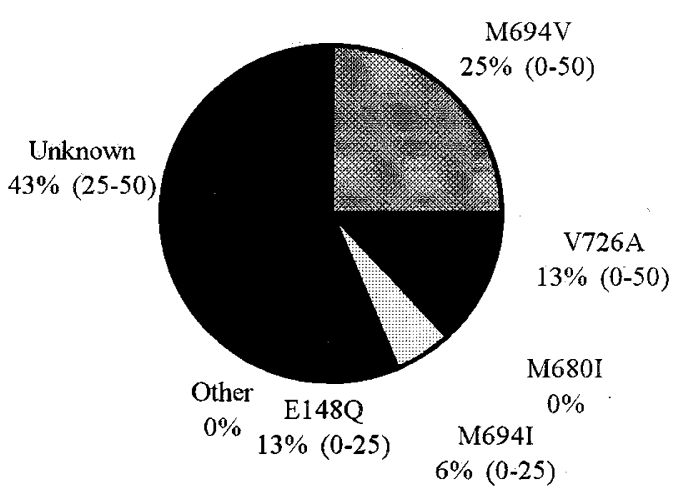

Figure 5 Repartition of MEFV mutations in European patients with possible FMF. Data are compiled from personal unpublished sources, R Manna and O Vougiouka (in preparation), and references for: (French), ${ }^{9}$ (Italians), ${ }^{3,9}$ (Spaniards), ${ }^{3,9,10}$ and (Greeks). ${ }^{3,9,11}$ These patients are not from classical ancestry. $\mathrm{N}=$ number of FMF chromosomes scored. Ranges are represented in parenthesis. Zeros refer to either absent or not studied mutations.

number of mutations known to date is relatively limited and only five of the 29 mutations are present in more than $1 \%$ of all FMF chromosomes, all patient ancestries pooled. In commonly affected countries, a limited screening leads to genetic confirmation in half to two thirds of the patients. However, the preferential occurrence of private mutations in patients from uncommon ancestry and the constant increase in mixed marriages make it necessary to carry out full MEFV screening to genetically confirm the diagnostic. The genetic test has to be interpreted cautiously if less than one mutation per inherited allele is found, especially in populations where the carrier rate reaches as much as $1: 3$ (Table 2). Some authors have suggested that mutations in the MEFV gene may confer certain advantages to the individual that could account for the very high carrier rate in these populations. ${ }^{6,57}$

Severity of the disease course would basically depend on the combination and the number of mutated alleles involved in the patient genotype. Additional alleles within and/or outside the gene would further modify the phenotype, promoting or preventing chronic complications. The trend drawn from the compilation of published data is that mutations occurring within a small region between codon 680 and 694 in exon 10 have a high penetrance, and a severe impact on the FMF course and presentation, and genotypes 
Table 1 Distribution of rare MEFV mutations and complex alleles

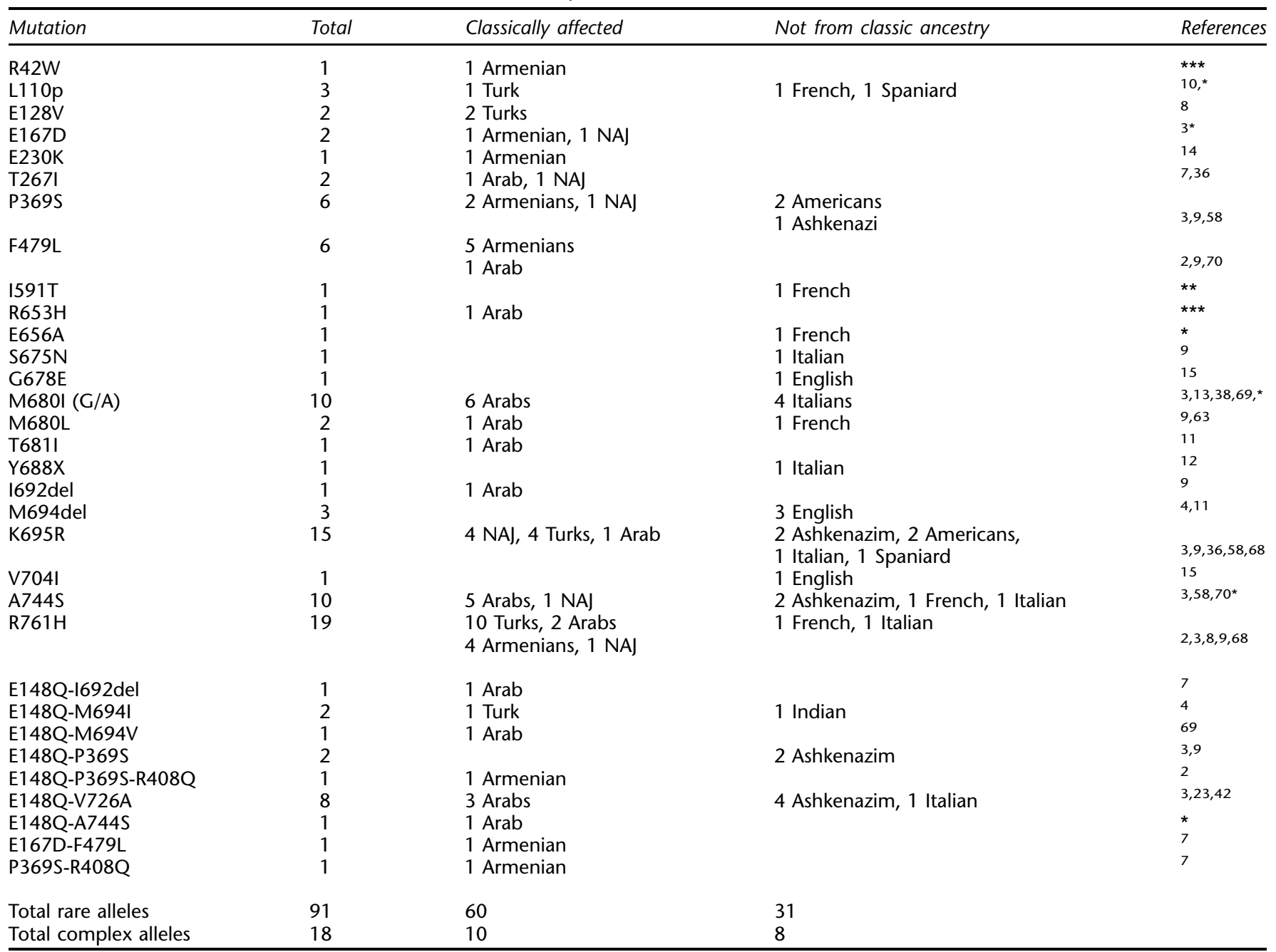

$\mathrm{NAJ}=$ Non Ashkenazi Jews. ${ }^{*}$ I Touitou, personal unpublished data. ${ }^{* *}$ D Cattan, E Throo, I Touitou, personal communication. ${ }^{* * *}$ I Aksentijevich, personal communication.

Table 2 Screening of the MEFV gene in the general population (healthy individuals)

\begin{tabular}{|c|c|c|c|c|c|c|c|c|c|}
\hline & \multicolumn{5}{|c|}{ Classically affected } & \multicolumn{4}{|c|}{ Not from classic ancestry } \\
\hline & Armenians & Iraqi-Jews & $N A J$ & Turks & Arabs & Indians & Chinese & Ashkenazim & British \\
\hline \multicolumn{10}{|l|}{ Gene frequency (\%) } \\
\hline Exon 10 mutations & 16.2 & 8.8 & 10.2 & 9 & 8.25 & ND & ND & 6 & ND \\
\hline Other mutations & 8.1 & 9.6 & 4 & ND & ND & 21 & 15 & 7.25 & 1 \\
\hline Total & 24.3 & 18.4 & 14.2 & $>9$ & 8.25 & $>21$ & $>15$ & 13.2 & $>1$ \\
\hline Carrier frequency (\%) & 37 & 30 & 24.4 & $>16.4$ & 15.1 & $>33.2$ & $>25.5$ & 22.9 & $>2$ \\
\hline Expected FMF prevalence (\%) & 5.9 & 3.4 & 2 & $>0.8$ & $>0.7$ & $>4.4$ & $>2$ & 1.7 & $>10^{-}$ \\
\hline References & 14 & 58,64 & $39,58,64$ & 29 & 38,65 & 44 & 44 & $3,58,66$ & 44 \\
\hline
\end{tabular}

Calculations were performed using the approximation of the Hardy-Weinberg law. NAJ: Non-Ashkenazi Jews, NDL not determined. Other mutations refers to E148Q for all populations. In Armenians and Ashkenazim, this line also includes other non exon 10 mutations.

including either V726A, P369S or E148Q are associated with a low penetrance and risk of amyloidosis. Some authors recommend early prophylactic colchicine life treatment in patients homozygous for M694V, emphasise the importance of screening family members for MEFV mutations, and consider the possibility of neonate systematic screening in 


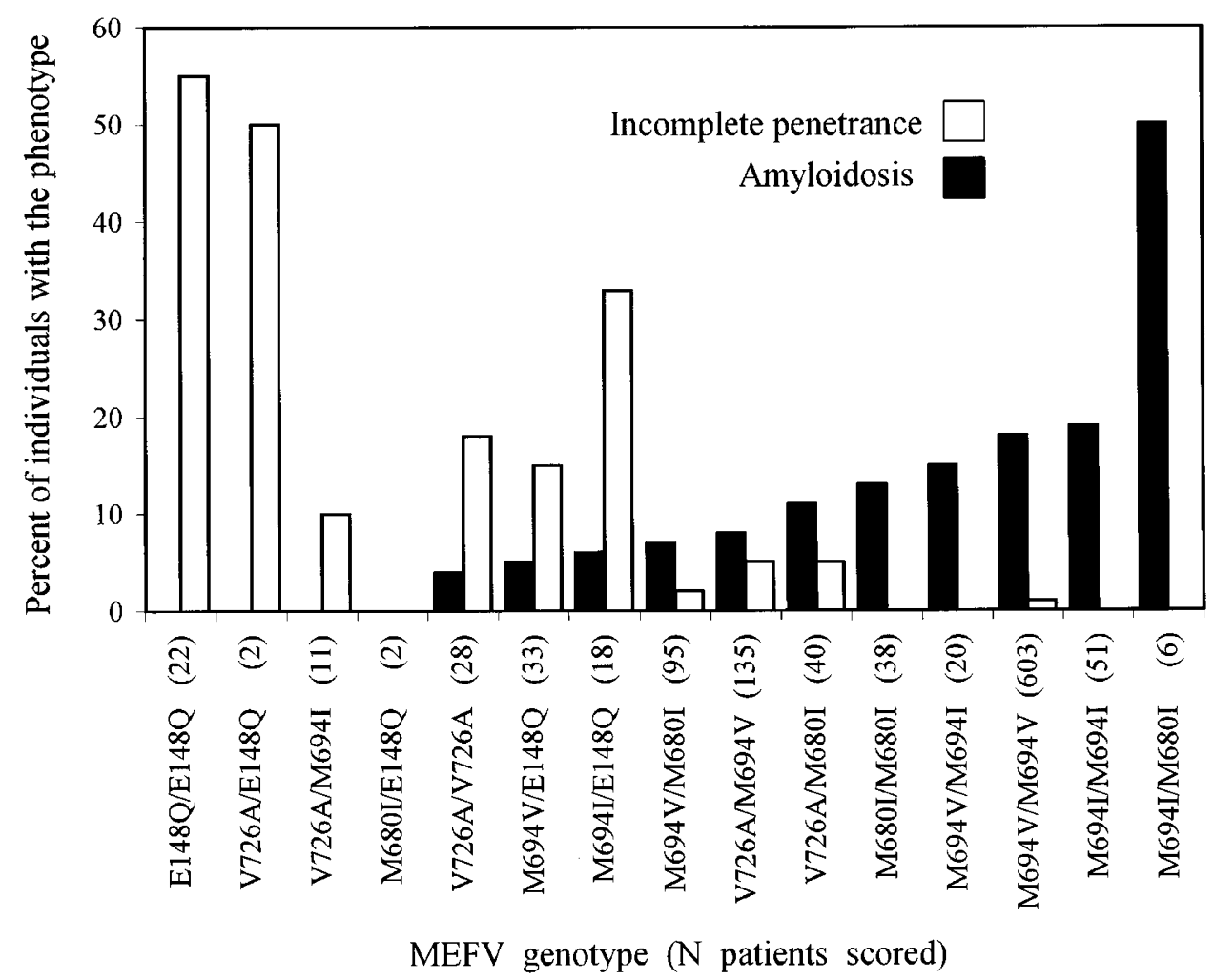

Figure 6 Phenotype-genotype correlation in FMF. This histogram is a compilation of published data $2-4,7-9,20,22,24,25,28,29,33,36,38,39,58$, $64,66,68,70,71$ and personal data. The two extreme phenotypes associated with the most frequent MEFV genotypes are represented. The percentage of patients presenting with FMF symptoms can easily be deduced from the percentage of patients with incomplete penetrance (for example, $100 \%-55 \%=45 \%$ for E148Q/E148Q; $100 \%-1 \%=99 \%$ for M694V/M694V). Note: Although interpretation of the data depicted here strongly depends on colchicine therapy, this information could not be implemented in this figure since it was lacking in most publications.

populations where this mutation is frequent. ${ }^{23,25,58}$ In patients with no severe genotype and a mild clinical disease, the question is whether a close follow-up of the renal function would be sufficient.

The overall phenotype of FMF patients is also likely to be influenced by non-genetic factors. This has been suspected for a long time following twin studies ${ }^{59}$ and from estimation of the prevalence of amyloidosis in untreated Armenians living in various countries: $<2 \%$ in California, ${ }^{60} 6 \%$ in Lebanon, ${ }^{61}>20 \%$ in Armenia. ${ }^{62}$ Indeed, the spectrum of MEFV mutations in Armenians was similar in all countries, demonstrating that the differences in the amyloidosis rates were not exclusively due to this genetic factor. ${ }^{20,21}$ Keeping this in mind, and the discordant results that have been described in Turks and Arabs series, ${ }^{33,34,43}$ comparative statistics implementing possible confusing factors such as access to treatment, consanguinity, ethnicity, etc..., are necessary to definitively elucidate the question of phenotype-genotype correlation in FMF. Therefore, both clinical and genetic data have still to be taken into account for the patient care.

\section{Note added in proof}

While this paper was in press, Schaner et al (Nature Genetics 2001; 27: 318-321) demonstrated that some amino acids that cause human disease are often present as wild type in primates. They suggest that the mutant represents the reappearance of an ancestral amino acid state in response to positive selection yet undefined.

\section{Acknowledgments}

This work was supported by the Centre Hospitalier de Montpellier (France). We thank Dr A Goldsborough for valuable suggestions and manuscript editing.

\section{References}

1 Heller H, Sohar E, Sherf L: Familial Mediterranean Fever (FMF). Arch Int Med 1958; 102: 50-71.

2 Cazeneuve C, Sarkisian T, Pêcheux C et al: MEFV gene analysis in Armenians patients with familial Mediterranean fever: diagnostic value, unfavorable renal prognosis of the M694V homozygous genotype, genetic and therapeutic implications. Am J Hum Genet 1999; 65: 88-97. 
3 Aksentijevich I, Torosyan Y, Samuels J et al: Mutation and haplotype studies in Familial Mediterranean Fever reveal new ancestral relationships and evidence for a high carrier frequency with reduced penetrance in the Ashkenazi Jewish population. Am I Hum Genet 1999; 64: 949-962.

4 Booth DR, Gilmore JD, Lachmann HJ, Pepys MB, Hawkins PN: The genetic basis of autosomal dominant familial Mediterranean fever. Q J Med 2000; 93: 217-221.

5 The French FMF consortium: A candidate gene for familial Mediterranean fever. Nature Genetics 1997; 17: 25 - 31 .

6 The International FMF consortium: Ancient missense mutations in a new member of the RoRet gene family are likely to cause familial Mediterranean fever. Cell 1997; 90: 797-807.

7 Bernot A, da Silva C, Petit JL et al: Non-founder mutations in the MEFV gene establish this gene as the cause of familial Mediterranean fever (FMF). Hum Mol Genet 1998; 7: 1317 - 1325.

8 Tunca M, Akar S, Booth DR et al: Familial Mediterranean fever in Western Turkey: five year experience in one institution. Abstracts of the familial Mediterranean fever II international conference, 3 - 7 May 2000, Antalya, Turkey. Clin Exp Rheumatol 2000; 18: D-2.

9 Dodé C, Pêcheux C, Cazeneuve C et al: Mutations in the MEFV gene in a large series of patients with a clinical diagnosis of Familial Mediterranean fever. Am J Med Genet 2000; 92: 241 246.

10 Domingo C, Touitou I, Bayou A et al: Familial Mediterranean fever in the Chuetas of Mallorca. A question of Jewish origin or genetic heterogeneity? Eur J Genet 2000; 8: 242-246.

11 Booth DR, Gillmore JD, Booth MB et al: Pyrin/Marenostrin mutations in familial Mediterranean fever. Q J Med 1998; 91: $603-606$.

12 Notarnicola C, Manna R, Rey JM, Touitou I: Y688X, the first nonsense mutation in familial Mediterranean fever (FMF). Hum Mutat 2001; 17: 79.

13 Magal N, Lotan R, Allon Shalev S, Khanaysi N, Shohat M: A new hot spot in the gene causing familial Mediterranean fever. Abstract of the 48th Annual meeting of the American Society of Human Genetics. Oct 28-31, 1998 Denver, USA. Am J Hum Genet 1998; 63(4 Suppl): A2155.

14 Torozyan Y, Aksentijevich I, Sarkisian T et al: Role of complex alleles and gender in susceptibility to Familial Mediterranean fever in Armenian population. Abstract of the 50th Annual meeting of the American Society of Human Genetics. Oct 3-7, 2000 Philadelphia, USA. Am J Hum Genet 2000; 67(4 Suppl): A227.

15 Lachmann HJ, Booth DR, Booth SE, Nash ST, Haskard DO, Hawkins PN: Two novel exon 10 MEFV mutations in a British man with an unclassified chronic inflammation diseasephenotype III FMF? Abstracts of the familial Mediterranean fever II international conference, 3-7 May 2000, Antalya, Turkey. Clin Exp Rheumatol 2000; 18: A-3.

16 Mansfield EA, Chae JJ, Komarow H, Brotz T, Centola M, Kastner DL: Pyrin, the FMF protein, colocalizes with microtubules in vivo and in vitro. Abstract of the 50th Annual meeting of the American Society of Human Genetics. Oct 3-7, 2000 Philadelphia, USA. Am J Hum Genet 2000; 67(4 Suppl): A931.17.

17 Papin S, Duquesnoy P, Cazeneuve C et al: Alternative splicing at the MEFV locus involved in familial Mediterranean fever regulates translocation of the marenostrin/pyrin protein to the nucleus. Hum Mol Genet ???; 9: 3001 - 3009.

18 Chae JJ, Centola M, Aksentijevich I et al: Isolation, genomic organization, and expression analysis of the mouse and rat homologs of MEFV, the gene for familial mediterranean fever. Mamm Genome 2000; 11: 428-435.

19 Livneh A, Langevitz P, Zemer D et al: Criteria for the diagnosis of familial Mediterranean fever. Arthritis Rheum 1997; 40: 18791885.

20 Mimouni A, Magal N, Stoffman N et al: Familial Mediterranean fever: Effects of genotype and ethnicity on inflammatory attacks and amyloidosis. Pediatrics 2000; 5: E70.
21 Dervichian M, Dodé C, Hovanessian Z et al: Amyloidosis prevalence in Armenians with familial Mediterranean fever (FMF). Abstracts of the familial Mediterranean fever II international conference, 3-7 May 2000, Antalya, Turkey. Clin Exp Rheumatol 2000; 18: E-3.

22 Dewalle M, Domingo C, Rozenbaum M et al: Phenotypegenotype correlation in Jewish patients suffering from familial Mediterranean fever (FMF). Eur J Hum Genet 1998; 6: 95 - 97.

23 Livneh A, Langevitz P, Shinar Y et al: MEFV mutation analysis in patients suffering from amyloidosis of familial Mediterranean fever. Amyloid 1999; 6: 1-6.

24 Pras E, Langevitz P, Livneh A et al: Genotype phenotype correlation in Familial Mediterranean fever (a preliminary report); in Sohar E, Gafni J, Pras M (eds): Familial Mediterranean Fever. Freund Publishing House: Tel Aviv, 1997, pp 260-264.

25 Shohat M, Magal N, Shohat T et al: Phenotype-genotype correlation in familial Mediterranean fever: evidence for an association between Met694Val and amyloidosis. Eur J Hum Genet 1999; 7: 287-292.

26 Shinar Y, Livneh A, Langevitz P et al: Genotype-Phenotype assessment of common genotypes among patients with Familial Mediterranean fever. J Rheumatol 2000; 27: 1703-1707.

27 Gershoni-Barunch R, Shinawi M, Kasinetz L et al: Ancient mutations in the FMF gene carrier frequency in different ethnic groups in Israel and genotype-phenotype correlation. Abstracts of the familial Mediterranean fever II international conference, 3-7 May 2000, Antalya, Turkey. Clin Exp Rheumatol 2000; 18: C-

28 Brik R, Shinawi M, Kepten I, Berant M, Gershoni Baruch R: Familial Mediterranean fever: Clinical and genetic characterization in a mixed pediatric population of Jewish and Arab patients. Pediatrics 1999; 103: E70.

29 Sayan N, Ozdogan H, Kasapcopur O et al: MEFV gene analysis in Familial Mediterranean fever patients from Turkey: Prognostic value of the M694V homozygous genotype. Abstracts of the familial Mediterranean fever II international conference, 3-7 May 2000, Antalya, Turkey. Clin Exp Rheumatol 2000; 18: C-15.

30 Yilmaz E, Akarsu N, Ozen S et al: Mutation analysis of MEFV gene in Anatolian FMF families and implication of independent segregation of two distinct genes. Abstracts of the familial Mediterranean fever II international conference, 3-7 May 2000, Antalya, Turkey. Clin Exp Rheumatol 2000; 18: A-9.

31 Sidi G, Shinar Y, Livneh A, Langevitz P, Pras M, Pras R: Protracted myalgia of Familial Mediterranean fever. Mutation analysis and clinical correlations. Scand J Rheumatol 2000; 29: 174-176.

32 Koné-Paut I, Dubuch M, Sportouch J, Minodier P, Garnier JM, Touitou I: Phenotype/genotype correlation in 91 patients with Familial Mediterranean Fever [FMF] reveals a high frequency of cutaneomucous features. Rheumatology 2000; 39: 1275-1279.

33 Yalcinkaya F, Cakar N, Misirlio M et al: Genotype-phenotype correlation in a large group of Turkish patients with familial Mediterranean fever: evidence for mutation-independent amyloidosis. Rheumatology 2000; 39: 67-72.

34 Tekin M, Yalcinkaya F, Cakar N, Akar N, Misirliogliu M, Cakar N: MEFV mutations in multiplex families with Familial Mediterranean fever: is a particular genotype necessary for amyloidosis? Clin Genet 2000; 57: 430-434.

35 Akar N, Yalcinkaya F, Akar N: Is Ala138Gly Alteration of MEFV gene important for amyloidosis. Hum Mutat 2001; (Mutation in brief\#382, online).

36 Mansour I, Delague V, Cazeneuve C et al: Familial Mediterranean fever in Lebanon: mutation, evidence for cases in Maronites, Greek Orthodoxes, Greek Catholics, Syriacs and Chiites and for an association between amyloidosis and M694V and M694I mutations. Eur J Hum Genet 2000; 9: 51-55. 
37 Cattan D, Dervichian M, Dode C et al: MEFV mutations and phenotype-genotype correlations in North African Jews (NAJ) and Armenians suffering from familial Mediterranean fever (FMF). Abstracts of the familial Mediterranean fever II international conference, 3-7 May 2000, Antalya, Turkey. Clin Exp Rheumatol 2000; 18: C-9.

38 Shinawi M, Brik R, Berrant M, Kasinetz L, Gershoni Baruch R: Familial Mediterranean fever: high gene frequency and heterogeneous disease among an Israeli - Arab population. J Rheumatol 2000; 27: 1492-1495.

39 Ben-Chétrit E, Lerer I, Malamud E, Domingo C, Abeliovich D: The E148Q mutation in the MEFV gene: Is it a disease-causing mutation or a sequence variant? Hum Mutat 2000; 15: 285-286.

40 Tamir N, Langevitz P, Zemer D et al: Late-onset Familial Mediterranean fever (FMF): a subset with distinct clinical, demographic, and molecular genetic characteristics. Am J Med Genet 1999; 87: 30-35.

41 Zaks N, Langevitz P, Kogan A et al: Non penetrant cases of double mutations in MEFV and mutations in phenotype II patients. Abstracts of the familial Mediterranean fever II international conference, 3 - 7 May 2000, Antalya, Turkey. Clin Exp Rheumatol 2000; 18: C-17.

42 Touitou I, Ben-Chétrit E, Notarnicola C et al: Familial Mediterranean Fever (FMF) clinical and genetic features in Druzes and Iraqi-Jews: a preliminary study. J Rheumatol 1998; 25: 916-919.

43 Majeed HA, El-Shanti H, El-Khateeb M: Genotype/Phenotype correlations in Arab patients with Familial Mediterranean fever: a preliminary study. Abstracts of the familial Mediterranean fever II international conference, 3-7 May 2000, Antalya, Turkey. Clin Exp Rheumatol 2000; 18: C-5.

44 Hawkins PN, Gillmore JD, Booth SE et al: Pyrin E148Q is prevalent globally and may upregulate the inflammatory response non-specifically. Abstracts of the familial Mediterranean fever II international conference, 3 - 7 May 2000, Antalya, Turkey. Clin Exp Rheumatol 2000; 18: A-4.

45 Touitou I, Picot MC, Domingo C et al: The MICA region determines the first modifier locus in familial Mediterranean fever. Arthritis Rheum 2001; 44: 163-169.

46 Cazeneuve C, Ajrapetyan H, Papin S et al: Identification of MEFV independent modifying genetic factors for familial Mediterranean fever. Am J Hum Genet 2000; 67: 1136-1143.

47 Akarsu AN, Saatci U, Ozen S, Bakkaloglu A, Besbas N, Sarfarazi M: Genetic linkage study of familial Mediterranean fever (FMF) to $16 \mathrm{p} 13.3$ and evidence for genetic heterogeneity in the Turkish population. J Med Genet 1997; 34: 573-578.

48 Touitou I, Magne X, Molinari N et al: MEFV Mutations in Behçet's disease. Hum Mutat 2000; 16: 271-272.

49 Livneh A, Aksentijevich I, Langevitz P et al: A single mutated MEFV allele in Israeli patients suffering from familial Mediterranean fever and Behcet's disease (FMF-BD). Eur J Hum Genet 2001; 9: $191-196$.

50 Ozdogan H, Sayhan N, Melikoglu M et al: MEFV gene mutations in Turkish patients with FMF amyloidosis versus other secondary amyloidosis. Abstracts of the familial Mediterranean fever II international conference, 3-7 May 2000, Antalya, Turkey. Clin Exp Rheumatol 2000; 18: E-5.

51 Brick R, Litmanovitch D, Berkwitz D, Shamir R, Shinawi M, Gershoni-Baruch R: High incidence of FMF mutations among children from Mediterranean extraction with recurrent abdominal pain. Abstracts of the familial Mediterranean fever II international conference, 3 - 7 May 2000, Antalya, Turkey. Clin Exp Rheumatol 2000; 18: F-2.

52 Cattan D, Notarnicola C, Molinari N, Touitou I: Inflammatory bowel disease in non-Ashkenazi Jews with Familial Mediterranean fever. Lancet 2000; 355: 378 - 379.

53 Fidder HH, Langevitz P, Pras M, Livneh A: Crohn's disease in patients with Familial Mediterranean fever. Abstracts of the familial Mediterranean fever II international conference, 3-7 May 2000, Antalya, Turkey. Clin Exp Rheumatol 2000; 18: F-7.
54 Fresko I, Masatioglu S, Melitlioglu M et al: The frequency of Familial Mediterranean fever (FMF) among patients with Behcet's syndrome (BD). Abstracts of the familial Mediterranean fever II international conference, 3-7 May 2000, Antalya, Turkey. Clin Exp Rheumatol 2000; 18: F-11.

55 Tunca M, Kirkali G, Soyturk M, Akar S, Pepys MB, Hawkins PN: Acute phase response and evolution of Familial Mediterranean fever. Lancet 1999; 353: 1415.

56 Tunca M, Akar S, Booth DR et al: The significance of paired MEFV mutations in individuals without symptoms of familial Mediterranean fever. Abstracts of the familial Mediterranean fever II international conference, 3-7 May 2000, Antalya, Turkey. Clin Exp Rheumatol 2000; 18: C-1.

57 Brenner-Ullman A, Melzer-Ofir H, Daniels M, Shohat M: Possible protection against asthma in heterozygotes for familial Mediterranean fever. Am J Med Genet 1994; 53: 172-175.

58 Stoffman N, Magal N, Shohat T et al: Higher than expected carrier rates for Familial Mediterranean fever in various Jewish ethnic groups. Eur J Hum Genet 2000; 8: 307-310.

59 Shohat M, Livneh A, Zemer D, Pras M, Sohar E: Twin study in Familial Mediterranean fever. Am J Med Genet 1992; 44: 179_ 182.

60 Schwabe AD, Peters RE: Familial Mediterranean fever in Armenians: analysis of 100 cases. Medicine (Baltimore) 1974; 53: $453-462$

61 Armenian HK: Genetic and environmental factors in the aetiology of familial paroxysmal polyserositis. An analysis of 150 cases from Lebanon. Trop Geogr Med 1982; 34: 183-187.

62 Aivazian AA, Zavgorodniaia AM, Abramian MK, Paskinian SA, Bagdasarian GB: Immunogenesis of periodic disease. Klin Med (Mosk) 1977; 55: 41-47.

63 Dodé C, Pecheux C, Cazeneuve C et al: Phenotype/Genotype correlations in Arab FMF patients. Abstracts of the familial Mediterranean fever II international conference, 3-7 May 2000, Antalya, Turkey. Clin Exp Rheumatol 2000; 18: C-8.

64 Shinar Y, Kogan A, Langevitz P et al: Frequency of V726A, E148Q and M694V mutations in the MEFV gene among healthy North African and Iraqi Jews. Abstracts of the familial Mediterranean fever II international conference, 3-7 May 2000, Antalya, Turkey. Clin Exp Rheumatol 2000; 18: C-13.

65 El-Shanti H, El-Khateeb MS, Tayeh M et al: Mutation analysis, genotype-phenotype correlation and carrier frequency of Familial Mediterranean fever in Jordan population. Abstract of the 50th Annual meeting of the American Society of Human Genetics. Oct 3-7, 2000 Philadelphia, USA. Am J Hum Genet 2000; 67(Suppl 4): A2234.

66 Kogan A, Shinar Y, Langevitz P et al: Frequency of V726A and E148Q mutations of the MEFV-gene among healthy Ashkenazi Jews in Israel. Abstracts of the familial Mediterranean fever II international conference, 3 - 7 May 2000, Antalya, Turkey. Clin Exp Rheumatol 2000; 18: C-12.

67 Gershoni-Baruch R, Kepten I, Shinawi M, Brick R: Direct detection of common mutations in the Familial Mediterranean fever gene (MEFV) using naturally occurring and primer mediated restriction fragment analysis. Hum Mutat 1999; 14: $91-95$.

68 Akar N, Misiroglu M, Yalcinkaya F et al: MEFV mutations in Turkish patients suffering from Familial Mediterranean fever. Hum Mutat 2000; 15: 118 - 119 .

69 El-Shanti HE, Majeed HA, Al-Khateeb M: Mutation analysis of the MEFV gene in the Jordanian population. Abstracts of the familial Mediterranean fever II international conference, 3-7 May 2000, Antalya, Turkey. Clin Exp Rheumatol 2000; 18: C2.

70 Medlej-Hashim M, Rawashdeh M, Chouery E et al: Genetic screening of fourteen mutations in Jordanian Familial Mediterranean fever patients. Hum Mutat 2000; 15: 384-390.

71 Press J, Shinar Y, Langevitz P, Livneh A, Pras M, Buskila D: Familial Mediterranean fever in two Bedouin families: Mutation analysis and disease severity. Am J Med Genet 2000; 92: 247-249. 